\title{
Antoine Fongaro, Le Soleil et la Chair. Lecture de quelques poésies de Rimbaud
}

\section{Mario Richter}

\section{(2) OpenEdition}

1 Journals

\section{Edizione digitale}

URL: http://journals.openedition.org/studifrancesi/6378

DOI: ERREUR PDO dans/localdata/www-bin/Core/Core/Db/Db.class.php L.34 : SQLSTATE[HYO00]

[2006] MySQL server has gone away

ISSN: 2421-5856

\section{Editore}

Rosenberg \& Sellier

\section{Edizione cartacea}

Data di pubblicazione: 1 novembre 2010

Paginazione: 576

ISSN: 0039-2944

\section{Notizia bibliografica digitale}

Mario Richter, «Antoine Fongaro, Le Soleil et la Chair. Lecture de quelques poésies de Rimbaud», Studi Francesi [Online], 162 (LIV | III) | 2010, online dal 30 novembre 2015, consultato il 08 janvier 2021. URL: http://journals.openedition.org/studifrancesi/6378; DOI: https://doi.org/10.4000/studifrancesi.6378

Questo documento è stato generato automaticamente il 8 janvier 2021.

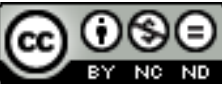

Studi Francesi è distribuita con Licenza Creative Commons Attribuzione - Non commerciale - Non opere derivate 4.0 Internazionale. 


\title{
Antoine Fongaro, Le Soleil et la Chair. Lecture de quelques poésies de Rimbaud
}

\author{
Mario Richter
}

\section{NOTIZIA}

ANTOINE FONGARO, Le Soleil et la Chair. Lecture de quelques poésies de Rimbaud, Paris, Éditions Classiques Garnier, 2009, pp. 240.

1 Indicando nel sole e nella carne (cioè la sessualità) i due poli che «aimantent toute la poésie rimbaldienne» e peraltro sottraendosi, come sempre ha fatto, a precipitose e fantasiose generalizzazioni, Antoine Fongaro ci offre in questo libro un'ulteriore prova del suo metodo, ovvero del suo sano desiderio di accostarsi a Rimbaud tramite «une lecture littérale méticuleuse du texte, attentive au moindre détail du vocabulaire, de la syntaxe, du style (images, tropes, etc.), du contenu et du contexte historique, politique, social, religieux» (p. 231). Naturalmente ciò non significa che questa attenzione ai particolari impedisca al critico di mantenere come meta sperata il senso generale dell'opera garantito dall'unità del genio del poeta di Charleville. L'A. comincia con un utile chiarimento circa il termine vesprée presente nel Cour supplicié, termine che non sarebbe ripreso direttamente da Ronsard col valore di un arcaismo ma da Musset e da Verlaine, venendo in tal modo a indicare "la poésie mièvre" di quei due poeti. Non meno interessanti, a proposito della stessa importante poesia a confutazione di alcuni aspetti della lettura di J. Bienvenu, risultano le osservazioni riguardanti le parole poupe e abracadabrantesques. È poi la volta di alme (nelle Soeurs de charité) e panadif (nella lettera a Demeny detta del Veggente), di vibrement e bombinent, di éclanches, di alcuni latinismi, di alcuni sintagmi (on sent un goût, tisonnant son cceur, pialats ronds, mains de cousine, la strideur des clairons ecc.). Segue un capitolo che costituisce un apporto significativo alla presenza, già in gran parte indagata, di Banville in Rimbaud. Il lettore troverà in seguito una serie di istruttive esegesi o precisazioni di testi come Les Premières communions, Le Bateau ivre, Larme (per quanto riguarda le rime), Bonne pensée du matin, Bannières de mai, Âge d'or (in rapporto a Verlaine), Fêtes de la faim e Faim 
nell'Alchimie du verbe (dove risulta demitizzata la pretesa povertà di Rimbaud), «Le loup criait», «La Folle par affection» nel decimo verso delle «Plates bandes d'amarantes». Guidato dal giusto principio che è il contesto a determinare il senso esatto di un termine impiegato, Fongaro si concentra sulla parola trépas per chiarire l'ultimo distico di «O saisons, o châteaux», dove appunto il contesto porta a capire che si tratta di un uso iperbolico del termine così come fu in uso nell'amore prezioso della poesia galante. Un'interpretazione analoga riguarda il coq presente nel terzo distico dello stesso testo, dove il sintagma "coq gaulois" sembra senz'altro designare l'organo sessuale.

2 Questo libro costituisce un utile apporto alla corretta comprensione di testi celebri di Rimbaud, spesso letti in una prospettiva chiaramente distorta. 